\title{
Towards systemic sustainable performance of TBI care systems: emergency leadership frontiers
}

\author{
Denis H. J. Caro
}

Received: 22 July 2010 / Accepted: 20 October 2010 /Published online: 10 November 2010

(C) The Author(s) 2010. This article is published with open access at Springerlink.com

\begin{abstract}
Background Traumatic brain injuries (TBIs) continue as a twenty-first century subterranean and almost invisible scourge internationally. TBI care systems provide a safety net for survival, recovery, and reintegration into social communities from this scourge, particularly in Canada, the European Union, and the USA.

Aims This paper examines the underlying issues of systemic performance and sustainability of TBI care systems, in the light of decreasing care resources and increasing demands for services.

Methods This paper reviews the extant literature on TBI care systems, systems reengineering, and emergency leadership literature.

Results This paper presents a seven care layer paradigm, which forms the essence of systemic performance in the care of patients with TBIs. It also identifies five key strategic drivers that hold promise for the future systemic sustainability of TBI care systems.

Conclusions Transformational leadership and engagement from the international emergency medical community is the key to generating positive change. The sustainability/ performance care framework is relevant and pertinent for consideration internationally and in the context of other emergency medical populations.
\end{abstract}

The views expressed in this paper are those of the author(s) and not those of the editors, editorial board or publisher.

D. H. J. Caro $(\bowtie)$

Telfer School of Management/École de Gestion Telfer,

University of Ottawa/Université d'Ottawa,

5141 Desmarais Building, 55 Laurier East,

Ottawa, ON K1N 6N5, Canada

e-mail: drcaro@uottawa.ca
Keywords Collaborative networks $\cdot$ Emergency medical leadership - Traumatic brain injuries · Performance Systemic sustainability

\section{Introduction}

Traumatic brain injuries (TBIs) continue to be a twenty-first century scourge that remains subterranean and mostly invisible in our societies [1-3]. These types of injuries represent only one of the myriad of emergency medical challenges faced daily and are ones that require policy redress regionally, nationally, and internationally [4]. War conflicts, firearms, violent assaults, vehicular dependence, high-risk sports participation, and public values and choices have contributed to this population health challenge with dire implications for health care costs and quality of life for its victims and society [5]. TBI care systems reduce mortality, morbidity, and suffering from neurotraumatic events. These care systems strive to promulgate positive outcomes with complete cognitive, functional, and physical recovery and reintegration of its victims into social milieus. Their prime mission is to foster social ecologies that mitigate the risk of TBIs; to deliver appropriate, effective, timely, and sustainable care; and to optimize cognitive, functional, and therapeutic outcomes for TBI patients. This is in keeping with the emergency care systems imperative to sustain life as a biological entity and recover the quality of life and complete physical, mental, social, and spiritual well-being for each person. Performance and effectiveness measures focus on outcomes that range from complete recovery and independence to a gradient of minor to severe disabilities to comatose and vegetative states to death. The effectiveness of resource deployment for positive TBI outcomes is part of the constellation of performance 
metrics. TBI care systems are composed of loosely coupled subsystems that tend to operate as largely discrete entities, or silos, each with their separate priorities and resource bases. Systemic sustainability is the ability of holistic systems to adapt to complex changes, while maintaining the capacity to attain set systemic outcome goals within reasonable resource parameters. Sustainable TBI care systems foster positive therapeutic and functional outcomes of TBI patients without significant increases in resources. With growing demands on emergency care resources and with the declining ability to meet these demands in many nations, current modalities for the delivery of TBI care are becoming increasingly unsustainable. In the face of external pressures, current TBI care systems risk collapsing into chaos. This paper explores seven care layers whose effective harmonization and integration form the basis of systemic performance and sustainability. An identification of five transformational changes and reflections on their future implications for systemic sustainability then follow.

\section{The TBI scourge}

TBIs are externally inflicted assaults that directly impact on the structure, physiology, and biochemistry of the brain, resulting in cognitive, functional, and physical changes and outcomes. TBIs are neither a strictly twenty-first century problem, nor are their neuropsychiatric consequences a recent phenomenon. TBIs are the most prevalent global cause of death and disability for people under 45 years and pose major international health and socioeconomic challenges. With an estimated incidence of TBI of 200 per 100,000 people, there are an estimated 46,461,200 new TBI cases annually in Canada, the European Union (EU), and the USA [6]. Of these, over $75 \%$ tend to be males under the age of 30 . TBIs carry mortality rates of $11 \%$, most of which occur within $48 \mathrm{~h}$ of the traumatic event. As a leading cause of permanent disability in Canada, the EU, and the USA, TBIs result from motor vehicle accident (MVA)-related events $(60 \%)$, sports-related injuries $(15 \%)$, work-related injuries (15\%), and violent assaults and suicides (10\%) [7].

TBIs are also the "signature wounds" of NATO troops who served in the wars in Afghanistan and Iraq [8, 9]. There is a significant and growing literature on war casualties that underscore the long-term societal impacts of TBIs [10-12]. Blast trauma from improvised explosive devices are the principal cause of mortality and morbidity of civilians and military personnel in war theaters and account for over $40 \%$ of combatants with TBIs [13-18]. Aside from causation, TBIs are classified on the basis of severity and whether they are open or closed (penetrating). Clinical screening tools, such as the Glasgow Coma Scale (GCS), assess case severity on the basis of visual, motor, and verbal functioning [19]. The determinants of poor prognostic TBI outcomes are diverse and include patient age; a GSC score of less than 5; the copresence of polytrauma, such as fractures, abdominal, and thoracic injuries; and delays in access to care [20]. Severe TBIs are a leading cause of death in Canada, the EU, and the USA with $90 \%$ of the mortality cases occurring within $48 \mathrm{~h}[21,22]$.

Moreover, mild traumatic brain injuries (m-TBIs) are difficult to identify and are often underdiagnosed with resulting risks of clinical complications and neuroworsening, as evidenced in patient cases of "talk and die" syndrome [23]. Cognitive recovery from TBIs remains clinically complex, individualistic, and unpredictable, making these injuries a silent public epidemic [24-32]. Over 16,000,000 Canadians, Europeans, and Americans face TBI-related disabilities lifelong. Neuropsychiatric sequelae are manifested through clinical depression and post-traumatic stress disorders, which affect over $40 \%$ of the TBI population for life [33]. Moreover, increased rates of sequelae are associated with higher rates of substance abuse, homelessness, and violence. The estimated annual health care costs and life years lost due to death and disability amount to over US $\$ 35,000$ per TBI case. Table 1 provides a profile of TBI cases and costs for Canada, the EU, and the USA.

\section{TBI care system performance layer model}

Systemic performance is integral to systemic effectiveness and efficiency. From the extant literature, one can discern seven layers of care for TBI patients. Positive cognitive and functional outcomes for TBI patients result from appropriate strategies and efficient resource deployment and effective performance at each of these discernible care layers. Positive systemic outcomes are in evidence only when TBI patients exhibit cognitive and functional improvements, if not, complete recovery from their initial clinical states consequent to traumatic events. The care of TBI patients crosses functional lines and organizational structures to form integrated systems with seven performance care layers, as illustrated in Fig. 1. The misalignment of strategies and mismanagement of resources at any level may adversely impact on the final outcome states of TBI patients.

Performance layer 1: field screening and TBI care interventions

Early identification and screening of TBI patients and appropriate care interventions are central to saving lives and mitigating complications. Paramedics with advanced trauma life support skill sets and competencies in the rapid clinical assessment of the severity of TBIs; polytrauma identification; hemorrhage control; hypotension, hypoxia, and neuro- 
Table 1 Profile of comparison of estimated TBI cases in 2010 in Canada, the EU, and the USA

${ }^{\mathrm{a}}$ Expressed as per 1,000 population

${ }^{\mathrm{b}}$ Expressed in billions of US dollars

\begin{tabular}{llll}
\hline Total estimated 2010 & Canada & EU & USA \\
\hline Population $^{\mathrm{a}}$ & 34,130 & 501,300 & 309,400 \\
TBI cases $^{\mathrm{a}}$ & 190 & 2,800 & 1,700 \\
Emergency unit visits of TBI cases $^{\mathrm{a}}$ & 160 & 2,300 & 1,400 \\
TBI hospital admissions $^{\mathrm{a}}$ & 320 & 450 & 280 \\
Discharged cases with TBI disabilities $^{\mathrm{a}}$ & 90 & 130 & 80 \\
TBI mortality cases $^{\mathrm{a}}$ & 6 & 84 & 52 \\
Population with TBI disabilities $^{\mathrm{a}}$ & 670 & 9,600 & 5,900 \\
Direct and indirect costs $^{\mathrm{b}}$ & US $\$ 6.76$ & US $\$ 97.2$ & US $\$ 60.0$ \\
\hline
\end{tabular}

worsening prevention; and intracranial pressure monitoring are all important [34].

Performance layer 2: logistical management and transit care of TBI patients

Optimal recovery from TBIs depends on the safe and effective evacuation by air, ground, or water to base hospitals for further patient stabilization, then to specialized neurotrauma care centers, as required. Effective logistical planning for rapid and safe transportation to these centers, while averting clinical complications, poses international emergency medical challenges of the first order. Here the skill sets and clinical competencies of critical care transport teams experienced in handling diverse transit issues are of paramount importance.

Performance layer 3: emergency TBI care units at base hospitals

Further screening, triage, and stabilization at emergency care units at base hospitals that have diagnostic and treatment capabilities to limit progressive neuroworsening and provide stabilizing conditions of patients with TBIs occur. However, even base hospitals may not have the full panoply of care resources, skill sets, and competencies essential for moderate and severe TBI patients. In such cases, the units serve as critical holding stations that resolve
Fig. 1 Seven-layer model of TBI care system performance

\section{Seven-Layer Model of TBI Care System Performance}

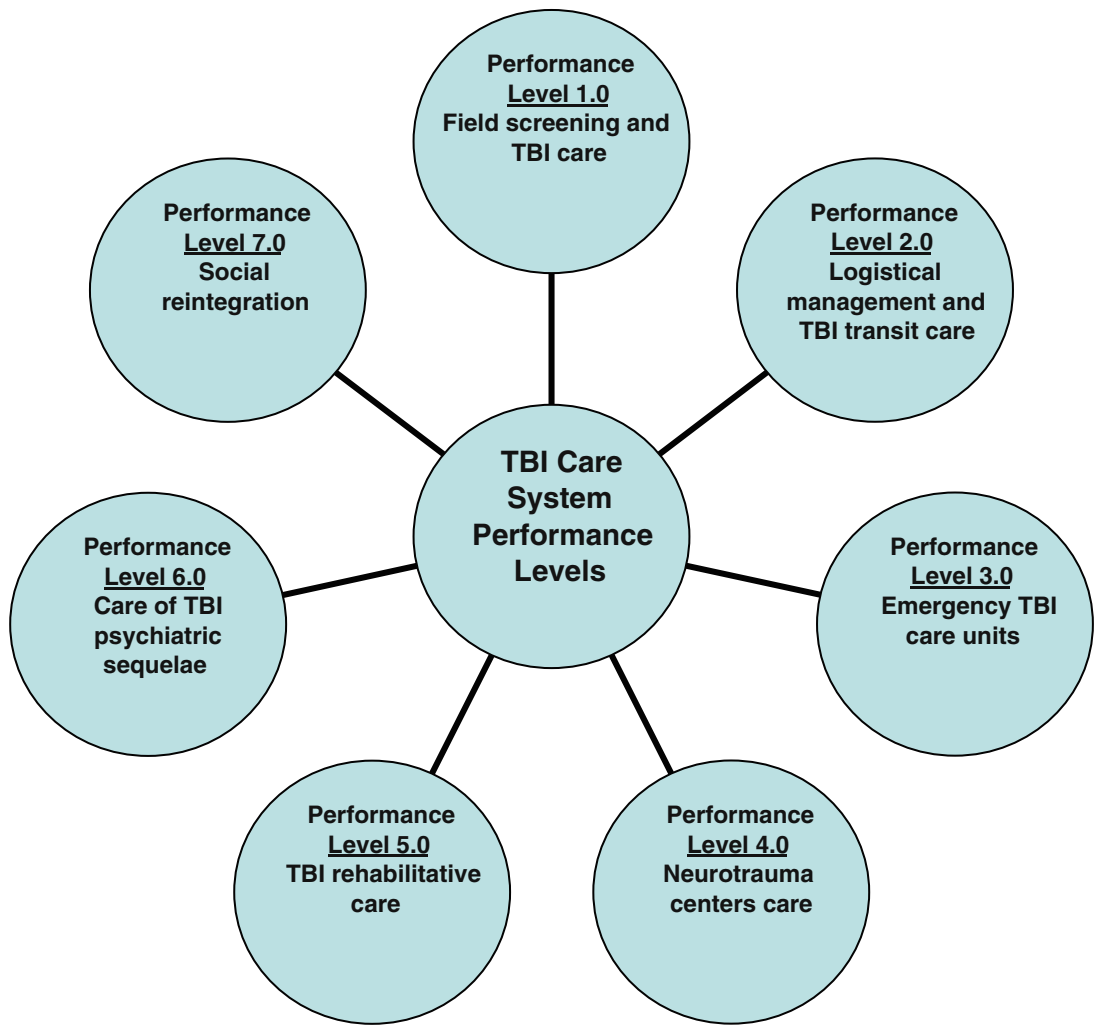


further logistical and clinical issues prior to transfer to more specialized neurotrauma centers.

Performance layer 4: TBI care through neurotrauma centers

Mortality rates of severe TBI are 2-15 times greater when patients are treated in non-neurosurgical centers, rather than neurotrauma centers with their full complement of specialized clinical resources and technologies [35]. Together with the gamut of advanced diagnostic tests and functional neuroimaging tools, these centers also provide further expertise in neurology, neuropsychology, neurosurgery, physical medicine, and psychiatry in response to the heterogeneity of TBIs and their comorbidities [36-40]. Skilled and experienced surgical interventions for debridements, hematomas, and operable lesions followed by advanced neurointensive care and recovery capabilities in infection controlled environments are integral to the care of TBI patients at these centers.

Performance layer 5: comprehensive TBI rehabilitative care

Early and intensive rehabilitation is important to optimal cognitive, functional, and therapeutic outcomes for patients with a range of TBIs. TBI impairments are invariably substantial, long-term, and decrease quality of life with marked limitations in personal independence and coping abilities. The ability of primary care providers to effectively identify and follow up on functional impairments of patients is crucial in minimizing the risks of complications and increasing the long-term chances of complete cognitive and functional recovery from TBIs [41-43]. Invariably, these patients require timely, efficient, and effective referrals to a wide gamut of professional clinical expertise, including those in audiology, behavioral therapy, cognitive rehabilitation and remediation, neuropsychology, occupational therapy, optometry, pharmacotherapy, psychotherapy, physical therapy, and speech therapy.

Performance layer 6: care for psychiatric sequelae of TBIs

TBI patients invariably manifest long-term psychiatric sequelae, such as bipolar disorders, clinical depression, generalized anxiety disorders, post-traumatic stress disorders, and significant personality changes [44-47]. These patients typically exhibit symptoms of avoidance behavior, hypervigilance, insomnia, and reoccurring nightmares-all of which impact negatively on their social functional capacities. Effective care coordination of community service providers within supportive environments is critical for the long-term psychosocial health of TBI patients [48]. Stigmatization poses further barriers to seeking necessary mental health care. TBI patients often turn to panoplies of deleterious substances that in turn propagate a cycle of increased addiction dependency, neuroworsening, alcoholrelated brain injuries, domestic violence, social isolation, homelessness, and further aggravation of underlying psychiatric sequelae. Suicide often becomes an ideation and sought as the final option for many with TBIs [49]. This underscores the need for early and effective psychological and psychiatric care intervention for TBI patients.

\section{Performance layer 7: social reintegration of TBI patients}

Physical impairments and cognitive, emotional, and behavioral dysfunctions present significant challenges when TBI patients are discharged and return to their respective home environments and social communities. The resumption of daily living activities, the maintenance of interpersonal relationships, and social functioning require time for readjustment. Effective care coordination and careful social reintegration planning strives to provide personal independence, supportive environments, and the highest quality of life for TBI patients [50-54]. Family education on TBI manifestations and caregiver responsibilities is important for positive outcomes and effective reintegration. Home care for TBI patients raises daunting challenges for families that face adaptive challenges of coping, grieving, and reintegrating as cohesive social units. Respite care planning and options are also important. Primary care providers, mental health professionals, occupational therapists, physiotherapists, and social work professionals all have pivotal care responsibilities for TBI patients as they readapt to their family units, work environments, and social communities [55]. Stable and positive living arrangements with emotional and financial support are essential for TBI patients and their families at this care layer.

\section{Strategic drivers of sustainable TBI care systems}

TBI care systems face the following paradox: as more care resources are deployed to promulgate life and quality of life for TBI patients at each care layer, the systemic sustainability of the system, from a holistic perspective, risks being compromised. As the number of TBI patients increases, the effectiveness and sustainability of current modalities of TBI care systems will become a public issue. Increasing case loads of a myriad of other afflictions, such as carcinomas, cardiovascular diseases, diabetes, infectious diseases, and psychiatric disorders will place unbearable strains on the sustainability of emergency and health care systems. To provide sustained quality levels of care in the face of diminishing resources and increasing cohorts of patients with TBIs, system transformation through reengineering will become essential. The application of lean thinking and systems reengineering techniques, such as process analysis, 
risk management, root cause analysis, and value analysis, to the TBI care processes holds the potential for greater efficiencies [56-58]. When applied to each care performance layer, these tools create opportunities to eradicate waste, avoid iatrogenic risks of misdiagnosis and underdiagnosis, reduce process duplication and resource redundancy, minimize waiting and transportation times, and eliminate processes that contribute little of direct benefit to TBI patients. Although focusing on each care layer independently is important in order to attain clinical performance targets and efficiencies, a holistic perspective of the entire TBI care system is also important. This "meso-layer" view militates against care system fragmentation and mitigates the risk of systems suboptimization, where resource imbalances compromise systemic performance, effectiveness, and sustainability. For example, significant clinical and financial resources must flow to support the effective performance of specialized neurotrauma centers, a care layer of paramount importance. In suboptimized scenarios, however, resources that support other key care layers may be deflected and may exacerbate long-term quality of life challenges of TBI patients. Such is the case when there is inadequate resource support for effective social reintegration of TBI patients into their respective milieus. Moreover, from a dynamic systems perspective, resource imbalances amplify over time. Severe resource constraints and increased cohorts of patients lead to a critical point, where the entire care system is no longer able to meet its performance objectives. In systems terms, this is the point of entropic decline and systemic chaos and signals the beginning of the collapse of the care system.

Another systems principle that comes into play is this: a system is only as coherent, stable, and strong as its weakest link. The weakest points in TBI care systems tend to occur at the nexus where TBI patients are transferred, or are discharged, from one care layer to another. Each nexus entails the transition of key accountabilities and responsibilities and evokes critical exchanges of information between care layers. These transitions need to be judiciously managed to assure seamless transfers of patients while providing continuity of TBI care. In essence, the care system must be horizontally integrated. This author posits that there are five strategic drivers that are germane to the continued performance and systemic sustainability of TBI care systems. As illustrated in Fig. 2, these systemic strategies include: (1) the creation of regional TBI collaborative networks, (2) the integration of intelligent system architectures, (3) the innovation and virtualization of care, (4) emergency medical leadership, and (5) societal value paradigm shifts.

Sustainability through regional TBI collaborative networks

Systemic sustainability requires both the horizontal and vertical integration of the care layer components. This connotes that there is a need for more structured networks that would promote more dynamic interactions, positive dialogue and communications, synergistic cooperation, and
Fig. 2 Strategic drivers of sustainable TBI care system performance

\section{Strategic Drivers of Sustainable TBI Care System Performance}

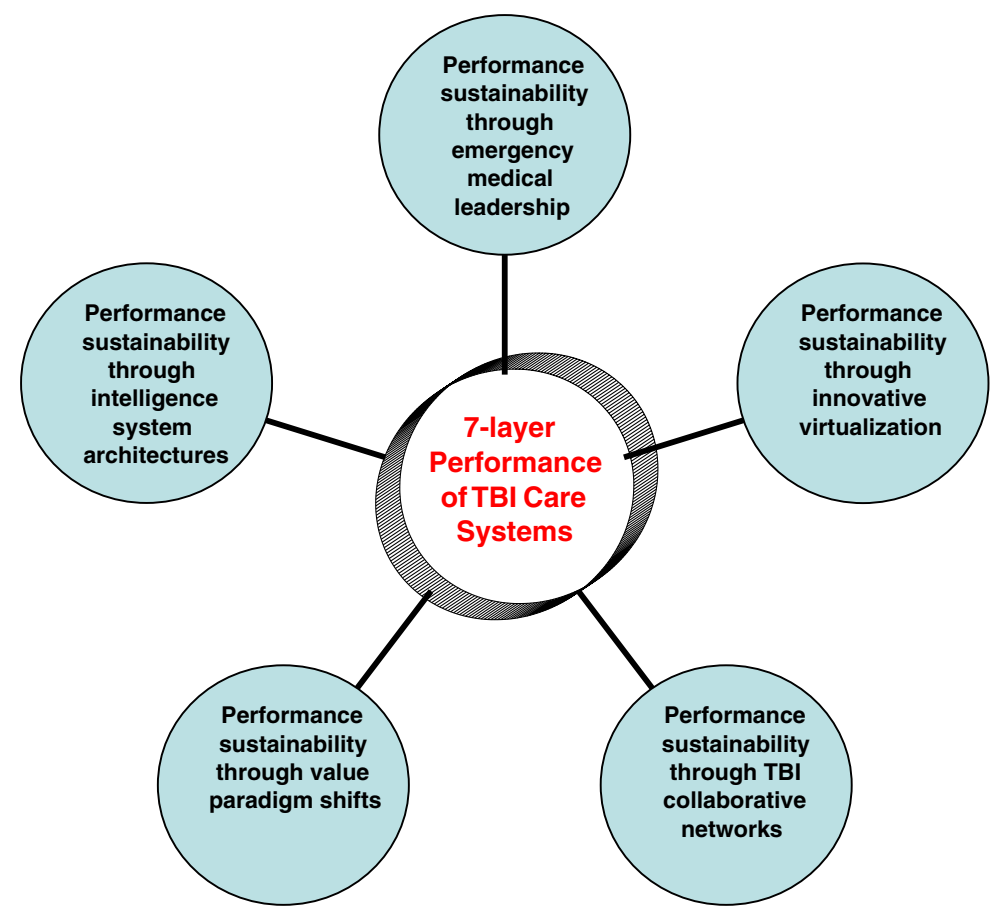


proactive collaboration between multidisciplinary and diverse professional communities and stakeholders within TBI care systems. Participants in these collaborative networks include: emergency medical communities; governance agencies and organizations that plan and finance care; clinical care providers; neurotrauma specialists; paramedical and field care services; professional associations; social service organizations; community care providers; and TBI patients and their families. Regionalization and centralization of specialized TBI care coordination through collaborative networks reduces redundancy and optimizes the deployment of diminishing resources in the face of increasing patient needs and demands. Effective coordination of care pathways of TBI patients from prehospital care to full social reintegration requires accountable and responsible regional oversight. Integrated regional accountability structures facilitate communications and foster trust relationships and enhance the effectiveness of TBI care processes systemically. Collaborative networks transcend fractured political jurisdictions and professional divides and promote systemic performance and sustainability for the benefit of patients with TBIs. TBI collaborative networks forge positive multidisciplinary links between TBI care professionals, patients, and families in pursuit of positive functional outcomes. These networks focus on efficient and effective resource deployment to reduce the mortality, morbidity, and neuropsychiatric sequelae of TBIs, thereby assuring systemic sustainability of care.

In Canada, the accountability for quality TBI care services still rests with individual care facilities. In the USA, the TBI Act of 2008 is the basis for the appropriation of financial resources for the continued development of TBI model systems centered on leading national brain research centers. Clear legislative mandates with sufficient and stable longterm financial and resource support from governance sources are essential for the future systemic sustainability of TBI care systems. In the absence of regionalized collaborative networks and vertically integrated structures, current TBI care modalities risk becoming unsustainable leading to systemic entropy, chaos, and collapse.

Sustainability through intelligence system architectures

TBI collaborative networks require effective exchanges and sharing of information and intelligence in professional environments that foster trust. Intelligence system architectures form the technological platform through which these networks take form and derive their substance. These architectures facilitate the implementation of advanced technological developments, such as cloud computing, data warehousing, clinical intelligence reporting, neural networks, as well as applications in social networking, interactive videoconferencing, and telemedical systems [59]. These technological capabilities enable the sharing of performance and outcome intelligence among care professionals in their battle to mitigate the mortality and morbidity rates and the appalling social costs of TBIs. The deployment of these architectures in emergency medical arenas has been inexorably slow in the absence of proactive leadership vision and public political will to introduce and finance these developments. Change is on the horizon, however. The promising deployment of portable smart health cards, slated for Canada and the EU by 2015 and perhaps the USA by 2020, will no doubt open the door to even greater technological changes that are built upon the foundation of intelligence systems architectures.

\section{Sustainability through innovative virtualization of care}

The increase of blast trauma injuries from improvised explosive devices in war theaters has ironically spawned a tele-revolution that has opened possibilities of a range of innovative technologies that will ultimately provide virtualized care. The innovative virtualization of care holds one of the keys to the future sustainability of the TBI care system. The TBI care systems world of the near future will also see dramatic and advanced innovations that will alter the nature of care processes for TBIs. Biomedical innovations in genetic therapy, pharmacology, and neuroscience will continue to progress towards earlier identification of pathophysiological brain changes and the regeneration of neurons [60]. These will include pervasive nanotechnologies to support remote neurological assessment systems, robotic neurosurgery, thought-controlled prosthetics, wear technologies with screening algorithms, neurocognitive testing linked to remote patient medical histories, and many other novel intelligent system applications in emergency medicine [61]. Developments in nanotechnologies will "transport" neurotrauma care teams providing neurointensive care in "virtual space" directly to traumatic event scenes to enhance advanced trauma life support in situ. Virtual neuroconsultations with polytrauma specialists internationally will become commonplace and will open the door to the possibility of outsourcing neuromedical care. Tele-community monitoring will facilitate the recovery, rehabilitation, and reintegration of TBI patients in home environments and social communities remotely and cost-effectively. Innovative virtualization will mitigate neuroworsening of TBI cases, overcome geospatial constraints, and prevent unnecessary high-risk aerial and ground transfersall with the intent to promulgate high care and continuity of care for TBI patients.

Sustainability through emergency medical leadership

Transformational leaders with the proactive vision and the ability to inspire and motivate others are the key to the 
continued systemic sustainability of TBI care systems. Leadership and the active engagement of emergency medical professionals, who are on the front lines of combating the scourge of TBIs, are integral to the emerging future landscapes of TBI care. Emergency medical leadership must forge cogent bonds with those in strategic governance positions to assure the continued flow of essential resources that will sustain effective performance of TBI care systems. Emergency medical leadership must cogently and courageously articulate strategic priorities to the public and must assertively foster positive dialogues between care providers, governance leaders, and stakeholders. It is this leadership that will stand the day on behalf of the scourge of TBIs and many other emergency aberrations that they encounter daily on the front lines of care.

Systemic sustainability through value paradigm shifts

Fundamental, yet crucial, challenges remain-ones perhaps best left for future generations. Conventional thinking in Canada, the EU, and the USA emphasizes the importance of legislative and regulatory controls, public safety awareness through education, effective policing services, the creation of safe work and recreational environments, and the promotion of neuroprotective technologiesall in the battle to prevent the deleterious impact of TBIs on society. Yet at the dawn of the twenty-first century, ours still remains essentially a violent society, one that inherently tolerates alcohol and substance abuse, firearms and weapons of violence, health destructive behaviors, vehicular overdependence, violent contact sports, and war conflicts driven through bloodlust media cultures. Occasional outcries from the outraged public are carefully filtered through media outlets and sometimes pressure politicians to legislate and regulate the excesses of unbounded violence, as in the case of the registration of firearms in Canada and in the EU. Nevertheless, current TBI care systems form a safety net for what are essentially violence-tolerant societies. Draconian prevention and health promotion strategies with zerotolerance policies for destructive health behavior are not part of the societal dictum, or public vision. Current consumer cultures do not yet universally and explicitly regard health and well-being as a critical and valued resource, a right of every human being, and a vital social investment for the future. Rather health continues to be associated with "sickness care" that drains societies financially with interminable health care and social costs. The view that health care is a fundamental human right conflicts with the prevailing economic dictum that health care is a societal cost. Economic and vested interests in the maintenance of violent cultures and societal impoverishment are still part of the social ethic and ecology and will not change likely for generations. Only psychological and social transformations of societal value constructs will change this
[62]. TBI care systems will continue to present social ecological challenges, until such time when humanitarian values of peace override propensities towards values that foster violence and destructive behaviors, until catastrophic war conflicts are resolved through peaceful resolution, and the right to health and well-being is unquestioned.

\section{Conclusion}

Traumatic brain injuries will continue to pose serious population health challenges, and the sustainability of care for TBI patients will be increasingly questioned in the face of growing health care needs and decreased resources. Faced with societal challenges, humankind always discovers and implements innovative strategies to meet and adapt to them. The current realpolitik of TBI care systems is leading to a fork in the road. Decreasing resources in the face of increased care needs will sooner, rather than later, lead to chaotic entropy of unsustainable care systems. Alternatively, with emergency medical leadership and responsible governance, regional collaborative networks founded on intelligence system architectures and innovative virtualized care will provide positive pathways towards systemic sustainability of the TBI care system. However, the greatest transformational challenge facing emergency medical leadership will still remain: that of transforming the conventional value landscape to one where the scourge of violence that results in TBIs is relegated to the darker annals of history. Perhaps in "time future" more enlightened societies that embrace values of nonviolence will pause to reflect how those in the emergency medical world managed so bravely in this "time present" of violence and its manifold manifestations. This is a call for the emergency medical community internationally to engage the public and collaborate proactively with other care professionals and governance in assuring the future sustainability of TBI care systems. In the absence of active engagement and leadership from those in emergency medicine, other professionals may heed the carillon call and the results may not be optimal for the future of emergency medicine and for TBI patients. Without proactive and collective engagement and transformational leadership, patients and care providers may have great hope for sustainable TBI care system, but may end up with "bleak house."

\section{Conflicts of interest None.}

Open Access This article is distributed under the terms of the Creative Commons Attribution Noncommercial License which permits any noncommercial use, distribution, and reproduction in any medium, provided the original author(s) and source are credited. 


\section{References}

1. Imhof HG, Lenzlinger PM (2005) Management of traumatic brain injury: application of guidelines for diagnostics and therapy. Eur J Trauma 31(4):331-343

2. Hulme J (2008) Resuscitation of patients after traumatic brain injury. Trauma 10(1):55-63

3. Park E, Bell J, Baker A (2008) Traumatic brain injury: can the consequences be stopped? CMAJ 178(9):1163-1170

4. Decker WW, Stead LG (2008) The International Journal of Emergency Medicine: a new journal for a new era. Int J Emerg Med 1(1):1-2

5. Anderson P, Petrino R, Halpern P et al (2006) The globalization of emergency medicine and its importance for public health. Bull World Health Organ 84:835-839

6. Langlois JA, Rutland-Brown W, WaId MM (2006) The epidemiology and impact of traumatic brain injury: a brief overview. J Head Trauma Rehabil 21:375-378

7. Cole TB (2004) Global road safety crisis remedy sought: 1.2 million killed, 50 million injured annually. JAMA 291:25312532

8. Snell F, Halter M (2010) A signature wound of war: mild traumatic brain injury. J Psychosoc Nurs Ment Health Serv 48 (2):22-28

9. Hayward P (2008) Traumatic brain injury: the signature of modern conflicts. Lancet Neurol 7(3):200-201

10. Okie S (2006) Reconstructing lives - a tale of two soldiers. N Engl J Med 355(25):2609-2615

11. Okie S (2005) Traumatic brain injury in the war zone. N Engl J Med 352(20):2043-2047

12. Warden DL, French L (2005) Traumatic brain injury in the war zone. N Engl J Med 353:633-634

13. Wolf S, Bebarta V, Bonnett C et al (2009) Blast injuries. Lancet 374(9687):405-415

14. Kocsis J, Tessler A (2009) Pathology of blast-related brain injury. J Rehabil Res Dev 46(6):667-672

15. Bhattacharjee Y (2008) Shell shock revisited: solving the puzzle of blast trauma. Science 319:406-408

16. Almogy G, Rivkind AI (2007) Terror in the 21st century: milestones and prospects-part I. Curr Probl Surg 44:496-554

17. Finkel MF (2006) The neurological consequences of explosives. J Neurol Sci 249:63-67

18. DePalma RG, Burris DG, Champion HR et al (2005) Blast injuries. N Engl J Med 352:1335-1342

19. Maas A, Stocchetti N, Bullock R (2008) Moderate and severe traumatic brain injury in adults. Lancet Neurol 7(8):728-741

20. Lemke DM (2007) Sympathetic storming after severe traumatic brain injury. Crit Care Nurse 27(1):30-37

21. Winslade W (2007) Severe brain injury: recognizing the limits of treatment and exploring the frontiers of research. Camb Q Healthc Ethics 16(2):161-168

22. Mathias JL, Wheaton P (2007) Changes in attention and information-processing speed following severe traumatic brain injury: a meta-analytic review. Neuropsychology 21:212-223

23. Bryant R (2008) Disentangling mild traumatic brain injury and stress reactions. N Engl J Med 358(5):525-527

24. Brooks JR (2008) Veterans' health system blazing trails. CMAJ 179(6):518-519

25. French LM, Parkinson GW (2008) Assessing and treating veterans with traumatic brain injury. J Clin Psychol 64:10041013

26. Sigford BJ (2008) "To care for him who shall have borne the battle and for his widow and his orphan" (Abraham Lincoln): the Department of Veterans Affairs polytrauma system of care. Arch Phys Med Rehabil 89(1):160-162
27. Keltner NL, Cooke B (2007) Biological perspectives: traumatic brain injury-war related. Perspect Psychiatr Care 43(4):223-226

28. Hoge CW (2006) Deployment to the Iraq war and neuropsychological sequelae. JAMA 296:2678-2679

29. Warden DL (2006) Military TBI during the Iraq and Afghanistan wars. J Head Trauma Rehabil 21(5):398-402

30. Chan RCK (2005) Sustained attention in patients with mild traumatic brain injury. Clin Rehabil 19:188-193

31. Ruff R (2005) Two decades of advances in understanding of mild traumatic brain injury. J Head Trauma Rehabil 20(1):5-18

32. von Wild KRH (2005) Neurorehabilitation following craniocerebral trauma. Eur J Trauma 31(4):344-358

33. Deb S, Burns J (2007) Neuropsychiatric consequences of traumatic brain injury: a comparison between two age groups. Brain Inj 21:301-307

34. Lew HL (2005) Rehabilitation needs of an increasing population of patients: traumatic brain injury, polytrauma, and blast-related injuries. J Rehabil Res Dev 42(4):xiii-xvi

35. MacKenzie EJ, Rivara FP, Jurkovich GJ et al (2006) A national evaluation of the effect of trauma-center care on mortality. N Engl J Med 354:366-378

36. Vaishnavi S, Rao V, Fann J (2009) Neuropsychiatric problems after traumatic brain injury: unraveling the silent epidemic. Psychosomatics 50(3):198-205

37. Bigler ED (2008) Neuropsychology and clinical neuroscience of persistent post-concussive syndrome. J Int Neuropsychol Soc $14: 1-22$

38. Blackbourne LH (2008) Combat damage control surgery. Crit Care Med 36(7 Suppl):S304-S310

39. Lew H, Cifu D, Sigford B et al (2007) Team approach to diagnosis and management of traumatic brain injury and its comorbidities. J Rehabil Res Dev 44:vii-xi

40. Lux WE (2007) A neuropsychiatric perspective on traumatic brain injury. J Rehabil Res Dev 44(7):951-962

41. Gutman S (2009) Special issue on brain injury: traumatic brain injury and stroke. Am J Occup Ther 63(5):523-524

42. Kokiko ON, Hamm RJ (2007) A review of pharmacological treatments used in experimental models of traumatic brain injury. Brain Inj 21:259-274

43. Phipps S, Richardson P (2007) Occupational therapy outcomes for clients with traumatic brain injury and stroke using the Canadian Occupational Performance Measure. Am J Occup Ther 61 (3):328-334

44. Stein MB, McAllister TW (2009) Exploring the convergence of posttraumatic stress disorder and mild traumatic brain injury. Am J Psychiatry 166(7):768-776

45. Keane TM (2008) Posttraumatic stress disorder: future directions in science and practice. J Rehabil Res Dev 45(3):vii-ix

46. King NS (2008) PTSD and traumatic brain injury: folklore and fact? Brain Inj 22:1-5

47. Keltner NL, Dowben JS (2007) Psychobiological substrates of posttraumatic stress disorder-part I. Perspect Psychiatr Care 43 (2):97-101

48. Neatherlin JS, Fox S (2006) End-of-life care concepts. J Neurosci Nurs 38(5):342-348, 353

49. Simpson GK, Tate RL (2007) Suicidality in people surviving a traumatic brain injury: prevalence, risk factors and implications for clinical management. Brain Inj 21:1335-1351

50. Daggett V, Bakas T, Habermann B (2009) A review of healthrelated quality of life in adult traumatic brain injury survivors in the context of combat veterans. J Neurosci Nurs 41(2):5971

51. Jaffee M, Helmick K, Girard P et al (2009) Acute clinical care and care coordination for traumatic brain injury within Department of Defense. J Rehabil Res Dev 46(6):655-666

52. Kondro W (2008) Inadequate surveillance. CMAJ 178:1534 
53. Petchprapai N, Winkelman C (2007) Mild traumatic brain injury: determinants and subsequent quality of life. A review of the literature. J Neurosci Nurs 39(5):260-272

54. von Steinbuechel N, Petersen C, Bullinger M et al (2005) Assessment of health-related quality of life in persons after traumatic brain injury-development of the QOLIBRI, a specific measure. Acta Neurochir Suppl 93:43-49

55. Wheeler D, Bragin M (2007) Bringing it all back home: social work and the challenge of returning veterans. Health Soc Work 32 (4):297-300

56. Banerjee A, Mbamalu D, Hinchley G (2008) The impact of process re-engineering on patient throughput in emergency departments in the UK. Int J Emerg Med 1(3):189-192

57. Decker WW, Stead LG (2008) Application of lean thinking in health care: a role in emergency departments globally. Int J Emerg Med 1(3):161-162

58. Lee CW (2006) Development of Web-based decision support system for business process reengineering in a health-care system. Acad Inf Manage Sci J 9(2):33-44

59. Girard P (2007) Military and VA telemedicine systems for patients with traumatic brain injury. J Rehabil Res Dev 44(7):1017-1026
60. Menon D, Harrison D (2008) Prognostic modelling in traumatic brain injury. BMJ 336:397-398

61. Varshney U (2005) Pervasive healthcare: applications, challenges and wireless solutions. Commun Assoc Inf Syst 16(1):1

62. Williamson J (2006) The disarmament, demobilization and reintegration of child soldiers: social and psychological transformation in Sierra Leone. Interv Int J Ment Health Psychosoc Work Couns Areas Armed Confl 4:185-205

Dr. Denis H. J. Caro is a Full Professor in MIS and Health Care Management at the Telfer School of Management at the University of Ottawa/Université d'Ottawa in Canada's capital. His research focus includes: emergency management systems; intelligence systems evaluation and auditing; strategic emergency leadership; and strategic interorganizational systems. Under the auspices of the Canadian College of Health Service Executives, he was the recipient of the MDS International Prize for the Study of Public/Private Partnerships in 2001 for his research entitled: "Strategic Partnerships between Leading IT Organizations and the Health Care Sector: Best Practices in Sweden, Germany and Canada." 